\title{
La escritura de los Incas a la luz de dos documentos jesuíticos secretos recién descubiertos
}

\author{
The Inca writing \\ according to two recently discovered jesuitic secret documents
}

Laura Laurencich Minelli

Resumen: Dos documentos jesuíticos recién hallados en un archivo italiano: Exsul Immeritus Blas Valera populo Suo (1616) del P. Blas Valera y Historia et Rudimenta Linguae Piruanorum, (final del siglo XVI-1638) de los italianos H. Antonio Cumis y P. Anello Oliva, narran de los quipu de los Incas como medio de comunicación en el ámbito de la reducción ante-litteram de Paititi (Virreinato del Perú). Estas nuevas fuentes sobre la escritura de los Inca, ponen en tela de juicio a Garcilaso de La Vega, por haber adaptado y recortado las fuentes valeranas sobre el tema de la escritura Inca de modo de caer bien, en sus Comentarios Reales (1609), con el poder hispano y al indio Guaman Poma por haber sido la pantalla de los jesuita -PP. Blas Valera, Anello Oliva y H. Gonzalo Ruiz- cual "autor" de la Nueva Coronica (1615) en el intento que esta gran carta al Rey resultara de un Natural.

Palabras Clave: escritura de los Incas, quipu, numerología, contrato Guaman PomaJesuitas, Paititi, P. Mutio Vitelleschi.

Abstract: Two Jesuit documents recently discovered in an Italian archive: Exul Immeritus Blas Valera populo Suo (1616) by F. Blas Valera and Historia et Rudimenta Linguae Piruanorum, (end of $16^{\text {th }}-1638$ ) by B. Antonio Cumis and F. Anello Oliva are telling us about the quipu writing as for communicating in the ante-litteram "Reduccion" of Paititi (Virreino del Peru). These new sources argue about the Inca writing described in the Comentarios Reales (1609), being adapted to the Spanish Power by Garcilaso de La Vega, and about the authorship of the Nueva Coronica (1615)

* Doctora. Universidad de Bologna, Italia. E-mail: laura.laurencich@unibo.it. Italia.

68 Laura Laurencich Minelli. La escritura de los Incas a la luz de dos documentos... 68 a 89. 
not beeing Guaman Poma's but Blas Valera's, Anello Oliva's and Gonzalo Ruiz's in order to have a Native writing to the King of Spain.

Key words: Inca writing, quipu, numerology, Guaman Poma/Jesuits contract, Paititi, P. Mutio Vitelleschi.

Recibido: 16 de julio de 2015

Evaluado: 28 de noviembre de 2015 
Dos fuentes jesuíticas halladas en el año 1997 en el archivo Miccinelli-Cera (Napoli): Exsul Immeritus Blas Valera populo Suo (1616) y Historia et Rudimenta Linguae Piruanorum, (final del siglo XVI-1638) respectivamente de mano del P. jesuita Mestizo Blas Valera y de los italianos H. Antonio Cumis y P. Anello Oliva, nos proporcionan elementos nuevos y muy curiosos sobre el tema de la escritura de los Naturales del Perú. Fuentes, que ya publiqué y de las cuales a seguir se proporciona el resumen: es decir no solo narran la compleja historia de estos dos documentos sino que, con documentos satélites, comprueban el intento del grupo jesuítico de revitalizar la escritura de los Inca en el ámbito de una reducción jesuítica (Paititi) ${ }^{1}$ : intento que Garcilaso de La Vega con sus Comentarios Reales (1609) adaptó y recortó de manera de caer bien con el poder hispano en el tema de la escritura de los Incas. Intento que, bajo el nombre del indio Guaman Poma, los PP. Blas Valera, Anello Oliva y el H. Gonzalo Ruiz proponen al Rey de España, gracias al apoyo del P. Mutio Vitelleschi. ${ }^{2}$

Aquí no entro en los detalles de la intriga pero me detengo sobre el tema de la escritura de los Incas que propone el grupo jesuítico en cuanto, al proporcionar razgos de la escritura del Tahuantinsuyu, nos permite vislumbrar el antiguo problema de la escritura de los Incas y el interés que los jesuitas tenían en mantenerla viva.

A seguir, sintetizo en orden cronológico lo que refieren las principales fuentes relacionadas con el grupo jesuítico y el tema de los quipu de los Incas: desde eso ya se desprende, en contra luz, el aporte novedoso que proporcionan las dos nuevas fuentes: Exsul Immeritus y Historia et Rudimenta.

\section{Las fuentes}

Garcilaso de la Vega el Inca, en sus Comentarios Reales, $1609^{3}$, al referir del jesuita P. Blas Valera y de la escritura mediante quipu, evidencia que los colores de las pendientes significan lo que se cuenta en aquel ramal: amarillo para el oro, blanco para la plata y colorado para la gente de guerra. Aclara que los nudos se daban por orden de unidad, decena, centena, millar, y "que los nudos de cada número de cada ramal iban parejos unos con otros, ni más ni menos que los pone un buen contador para hacer una suma grande". Además Garcilaso refiere que se "tenían señales que mostraban los hechos hazañosos" y sigue explicándonos que los quipucamayos escribían "mediante los quipu y los nudos de número, poesía y hechos históricos". Agrega que a ellos acudían los curacas y los hombres nobles en sus provincias y que los quipucamayos, al igual que nuestros escribanos y/o historiadores, antes de responderle, miraban a los quipu que "narraban" eso. Concluye que así los naturales conservaban la memoria. Descripción de Garcilaso (Libro VI, cap. IX, 1609 (1977:409) que resulta superficial, al

\footnotetext{
${ }^{1}$ Laurencich-Minelli, 2011.

${ }^{2}$ El P. jesuita mestizo Blas Valera nace en Chachapoya en 1545. Ingresa a la Compañía de Jesús en 1568 , exiliado del Perú el 11 de diciembre 1592, llega a España apenas en 1595, después de haberse detenido en Quito y Cartagena. Los dos documentos Exsul Immeritus e Historia et Rudimenta refieren que con el tácito permiso del P. Vitelleschi y la ayuda de otros cofrades, P. Blas muere jurídicamente en 1597 en Cádiz, para luego zarpar, bajo el nombre Ruruiruna, en junio de 1598 hacia el Perú y entrar en El Cuzco en 1599 dónde empieza su lucha a favor de los indígenas. Anello Oliva (Napoli 1574, Lima 1642) lo encuentra en 1611 en Santa Cruz de la Sierra cuando estaba ya escribiendo aquella gran carta al Rey que es la Nueva Coronica. P. Blas regresa a España en 1618 dónde escribe Exsul Immeritus Blas Valera Populo Suo (1618) para el P. Vitelleschi, en el cual brinda la descripción de su vida y también del complejo sistema de escritura de los quipu. Muere realmente en 1619 en Alcalá de Henares de acuerdo al napolitano P. Anello Oliva (Historia et Rudimenta (1637).

${ }^{3}$ Garcilazo de la Vega, 1977: 445-447, Libro VI, capítulo VIII.

70 Laura Laurencich Minelli. La escritura de los Incas a la luz de dos documentos... 68 a 89.
} 
compararla con cuanto le corrige luego el P. Jesuita en Exsul Immeritus, e incompleta tanto que abrió varios problemas a nuestros estudiosos: como por ej. ¿cual es la técnica para distinguir que un quipu, cuyos ramales son amarillos, trata de oro en vez del maíz, ambos de color amarillo?.

La Nueva Coronica y Buen Gobierno, escrita en 1615, que se consideraba el estendarde de la capacidad escritora de un Natural: Guayan Poma de Ayala, seria en cambio, de acuerdo a los documentos jesuíticos Exsul Immeritus Blas Valera populo suo e Historia et Rudimenta Linguae Piruanorum, de mano de los jesuitas P. Blas Valera, H. Gonzalo Ruiz y P. Anello Oliva, a los cuales Guamán Poma de Ayala "vendió" su autoría (1614). La Nueva Coronica describe no sólo el pasado incaico y el uso genérico de los quipu, sino mediante los tocapu (ideogramas) que figuran en forma profusa en los textiles inca de las viñetas de la misma obra, brinda un relato paralelo que se puede ahora leer gracias a la llave de lectura que de estos mismos tocapu proporcionan los dos documentos jesuíticos arriba mencionados: resulta una curiosa historia indígena sobre los Incas que publicaré pronto.

Los documentos jesuíticos Exsul Immeritus Blas Valera populo suo (1618) e Historia et Rudimenta Linguae Piruanorum (final del siglo XVI-1638) -el primero de mano del Padre mestizo Blas Valera y el segundo de los italianos H. Antonio Cumis y P. Anello Oliva pero con el cierre del P. Pedro de Illanes (1737)- nos proporcionan dos fuentes recién descubiertas en Italia (1994-1997) sobre los quipu que integran no solo las dos fuentes arriba mencionadas pero también aclaran que la Nueva Coronica no es de la mano del indio Guaman Poma de Ayala sino de los jesuitas P. Blas Valera, P. Anello Oliva y del H. Gonzalo Ruiz que "compraron" a Guaman su autoría a cambio de un caballo y de una carreta.

Como ambas fuentes Exsul Immeritus y Historia et Rudimenta han sido ya publicadas integralmente y discutidas ${ }^{4}$, aquí apenas las resumo: se trata de dos documentos secretos, escritos para dar a conocer, a quien logre leerlos, eventos importantes que contrastan con la historia "oficial" entre la cual el hecho de que la muerte de P. Blas en 1597 en Cádiz fue una falsa muerte apoyada por el P. Mutio Vitelleschi y otros cofrades, para permitirle al exiliado y "difunto" $P$. Blas su regreso al Perú bajo el nombre de Ruruiruna con el intento de que redacte aquella gran carta al Rey, la Nueva Coronica, con la cual se denuncia que la victoria de Cajamarca no ha sido obtenida con el honor de las armas pero brindando vino envenenado a la hueste de Atahuallpa. Intento que, a pesar de ser secreto, resultaba ya conocido a la administración hispana por lo menos desde el 1610 como se desprende de las dos cartas que el Lic. Boan escribe al Virrey ${ }^{5}$.

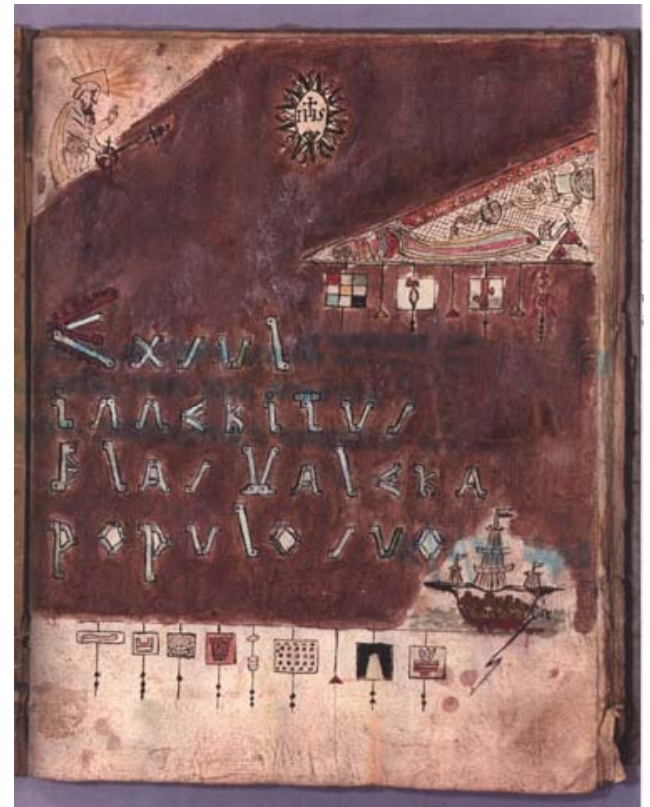

Fig. 1. Portada de Exsul Immeritus (col. Miccinelli-Cera, Nápoles).

\footnotetext{
${ }^{4}$ Laurencich-Minelli, 2007 y 2009.

${ }^{5}$ Ver las dos cartas del Lic. Boan al Virrey de Napoles con las cuales el Licenciado denuncia, en forma criptica, que el "difunto" Blas Valera estaba de vuelta en el Perú bajo el nombre Ruruiruna y estaba
}

71 Laura Laurencich Minelli. La escritura de los Incas a la luz de dos documentos... 68 a 89. 
El P. Blas Valera escribe el ms. Exsul Immeritus en Alcalá de Henares el año 1618, un año antes de su muerte real. Él narra en el mismo manuscrito (c. 2v) que ha sido su abuelo materno Illavanqa la persona que lo inició a los quipu y a la escritura andina aun antes de ingresar en la Compagnia (1568). Escribe Exsul en latín y quechua (Fig. 1), en latín mediante escritura alfabética y en quechua mediante escritura tradicional (quipu y tocapu). El ms. Exsul presenta muchos anexos: el más antiguo es la carta con la cual el conquistador Francisco de Chaves (Cajamarca, 5 de Agosto de 1533) denuncia al Rey que la victoria de Cajamarca no ha sido obtenida con el honor de las armas sino brindando vino envenenado a la hueste del Inca. El manuscrito contiene, en un sobre, también dos quipu numéricos: uno de lana, de color rojo y amarillo, y otro de hilo de oro. El primero es un quipu numérico de posición, el segundo es un quipu mixto: es decir, presenta 4 cordeles de quipu numérico de posición y tres de quipu de escritura. Además, Exsul Immeritus anexa, completamente sellado en una cajita, el curioso "contrato" con el cual en: Huanca el 16 de febrero 1614, los jesuitas Anello Oliva, Gonzalo Ruiz y Blas Valera "compraron" a Guamán Poma de Ayala la autoría de la Nueva Coronica, en cambio de un caballo y de una carreta (Fig. 2).

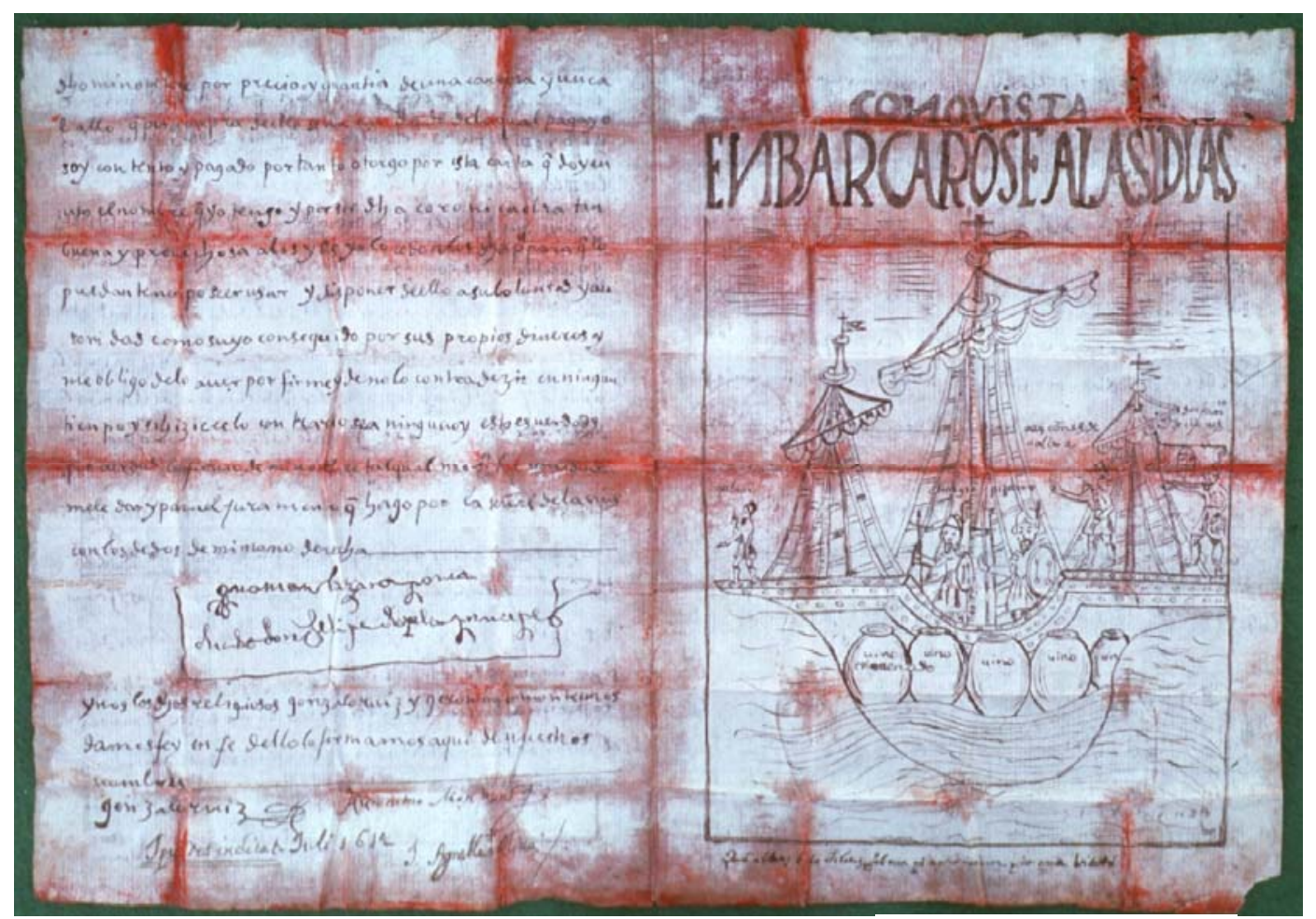

Fig. 2. Página del contrato entre los jesuitas y Guaman Poma de Ayala para la Nueva Coronica (col. Miccinelli-Cera, Nápoles).

\section{El quipu numérico}

El quipu más conocido es el quipu numérico. El primer estudio interpretativo de este quipu remonta al año 1912 y se basa en la confrontación entre el análisis crítico de las fuentes -antes del descubrimiento de Exsul Immeritus y Historia et Rudimenta- y el corpus de los quipu custodiados en los museos y colecciones de antigüedades peruanas. Sin embargo, el estudio del quipu numérico empieza con el estudio de L. L. Locke,

redactando la denuncia de Francisco de Chaves sobre la falsa victoria de Cajamarca, eso es parte de la Nueva Coronica. Cfr, Archivio di Stato, Napoli, Segreteria del Viceré, Scritture Diverse n.2, n.5, Viglietti, vol. 241,. Ver Cantú 2001 para la discusión y la lectura de las dos cartas.

72 Laura Laurencich Minelli. La escritura de los Incas a la luz de dos documentos... 68 a 89. 
publicado en 1912 que, gracias a la lectura de Garcilaso de La Vega ${ }^{6}$, encuentra la clave para leer los nudos y entender el significado numeral de este tipo de quipu. Estudio que sigue hoy en día ${ }^{7}$.

La lectura numeral del quipu numérico evidencia que los antiguos peruanos, tuvieron dos grandes privilegios, en el campo de la historia de la humanidad: 1) haber practicado la matemática de posición; 2) haber reconocido el valor del número 0 (la cuerdecilla sin nudos) en el ámbito de la Edad Antigua, al igual que los Hindú y los Mayas. En cambio eso era desconocido para los antiguos griegos y romanos y para el mundo europeo hasta mediados del siglo XV.

No me detengo sobre la lectura numeral del quipu numérico en cuanto el tema es bien conocido y se puede desprender de Fig. 3.

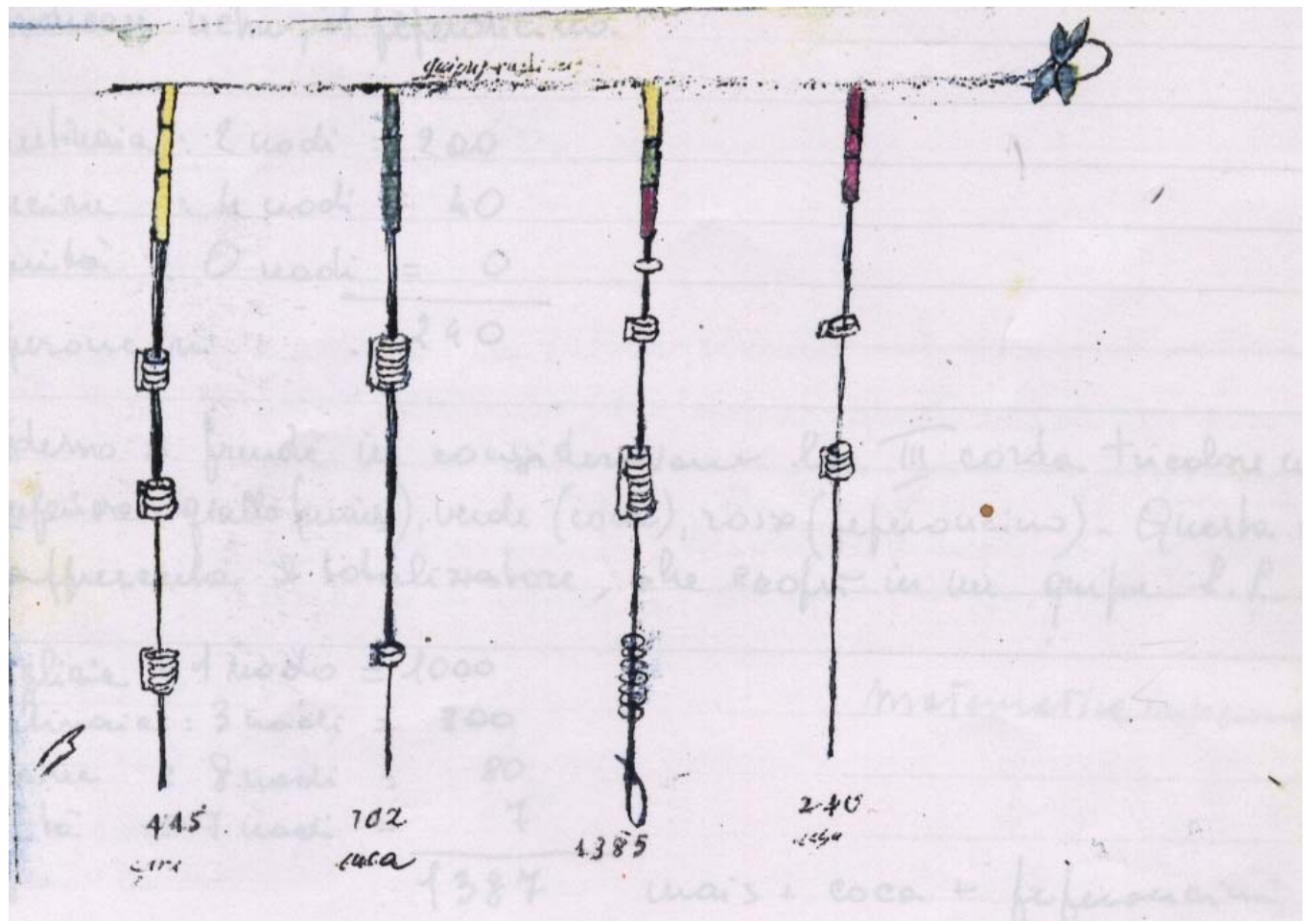

Fig. 3. Quipu numérico de posición con indicador de la clase agrícola (Exul Immeritus. Col. Miccinelli-Cera, Nápoles).

\section{2a. El aspecto extra numeral del quipu numérico}

El desciframiento del quipu de número se limita sólo al aspecto numérico de los nudos. En cambio, el aspecto extra numeral del quipu, es decir, el elemento narrativo que acompañaba a los números allí registrados, está todavía en discusión a pesar de que el documento Exsul Immeritus proporciona datos importantes y nuevos que integran lo que Garcilaso de la Vega (Libro VI, Cap. VIII) describe: por ejemplo como los colores

\footnotetext{
${ }^{6}$ Garcilaso de la Vega, 1609: Libro VI, capítulo VIII.

${ }^{7}$ Cfr.:Ascher M. y R. Ascher 1969, 1975, 1978, 1981, 1986, Concklin 1982, Laurencich-Minelli 1999 , 2001b, 2004b, 2006a, 2007 (ed,), L. Loke 1912, 1923, Radicati di Primeglio 1979, Urton 1995, 2003, Zuidema 1989.
} 
y otros elementos de las cuerdecillas permiten conocer el significado extra numeral de lo que ellas cuentan ${ }^{8}$.

Gary Urton había ya observado que las direcciones del giro impuesto a los colgantes y a los nudos pueden significar algo: de hecho pueden ser en $\mathrm{S}$, o dextrógiros y en $\mathrm{Z}$ o levógiros, según si el giro dado a los hilados que forman cada una de las cuerdecillas y/o el nudo, esté hacia la derecha o hacia la izquierda ${ }^{9}$.

El ms. Exsul Immeritus (c.8) nos aclara (1997) que los nudos en S o dextrógiros significan suma al igual que la mercancía entrante y los nudos en $\mathrm{Z}$ o levógiros significan resta al igual que la mercancía prevista y no entrada; al mismo tiempo refiere que la torsión de la colgante puede proporcionar la calidad de la mercancía apuntada en el quipu: es decir cuando está en $\mathrm{Z}$ significa que la mercancía allí registrada es de buena calidad, cuando está en $\mathrm{S}$ que es de mala calidad o que está podrida. En otras palabras, ese sería la base del mecanismo utilizado por los Incas para la teneduría de libros mediante quipu: algo sencillo y práctico que, con una sola lectura, proporciona los ingresos previstos y no efectuados, la calidad de la mercancía registrada.

Además el P. Blas, al quejarse en Exsul Immeritus de la manera superficial con la cual Garcilaso de La Vega presenta los quipu de número, nos introduce también otro elemento básico para su lectura: el indicador de clase, que él llama señal: eso nos permite interpretar el significado de los colores de las cuerdecillas. Indicador de clase que, al encabezar el quipu, adscribe la mercancía allí contada a una clase, hoy diríamos a una etnocategoría, de manera que, por ejemplo el color rojo de los cordeles indica el cinabrio, cuando el quipu pertenece a la clase de los minerales y el ají cuando en cambio pertenece a la clase agrícola (Cfr. Fig. 3).

La existencia de etnocategorías en el sistema de quipu andinos no es nueva. Sin embargo, Murra las plantea en los quipu que conciernen el Memorial presentado en 1561 por los curacas de Jauja a la Audiencia de Lima ${ }^{10}$.

La lectura del aspecto extra numeral del quipu numérico está todavía lejos de vislumbrar el significado que eso proporcionaba al quipucamayoc, a pesar de que hemos ya aclarado varios aspectos de ello: por ejemplo la dirección de los nudos de las colgantes que permite al quipu la función de libro de partida doble, la torsión de la colgante en $\mathrm{S}$ o en $\mathrm{Z}$ que proporciona la calidad de la mercancía registrada, el indicador de clase que evidencia la etnocategoría a la cual pertenece la mercancía. Sin embargo no se aclararon todavía muchos otros elementos, como por ejemplo no sabemos todavía

\footnotetext{
${ }^{8}$ La investigación arqueológica proporciona los siguientes colores de los quipus numéricos: blanco, azul, amarillo, rojo, negro, verde, gris y marrón; este último en tonos claros y obscuros. La mezcla entre estos colores produce muchas combinaciones. Las combinaciones de colores que se hallan con más frecuencia en los quipu son: blanco mezclado ya sea con negro, con azul, o con verde, pero sobre todo con marrón. El color rojo, por su parte, se encuentra mezclado, además del marrón, con el color amarrillo. En la combinación de colores no interesa solamente la unión cromática sino también el modo en que los colores están mezclados en una misma cuerdecilla. Por ej.: el sistema más simple es el de retorcer entre sí dos hilados de colores contrastantes: eso a su vez puede dar origen a dos posibilidades, una es que la cuerdecilla esté hecha de un grupo de hilados de un solo color torcidos entre sí y por otro grupo de hilados de color opuesto bien torcidos entre sí: el retorcer los dos grupos juntos proporciona una cuerdecilla bicolor. El otro caso es que la cuerdecilla esté hecha de dos grupos de hilados de colores mixtos retorcidos entre sí. En el primer caso, se hablará de coloración simple, en el segundo caso de coloración compuesta o marmoleada.

${ }^{9}$ Urton, 1995.

${ }^{10}$ Murra, 1975.
}

74 Laura Laurencich Minelli. La escritura de los Incas a la luz de dos documentos... 68 a 89. 
que significan los nudos en $\mathrm{S}$ o en $\mathrm{Z}$ con que se amarran las cuerdecillas a la cuerda maestra y el predominio de un color sobre otro en la mezcla de colores de las colgantes.

En otras palabras, estamos aún lejos de la lectura que de los quipu numéricos hacían los quipucamayoc en el antiguo Perú, a quienes les era confiado este maravilloso instrumento mnemónico, pero estamos ya cumpliendo unos pasos para entender esta inquietante combinación de símbolos, colores, posiciones e indicadores de clase, puesto que ahora nos damos cuenta que una de las que se suponía fuente básica sobre los quipu numéricos: Garcilaso de La Vega, había simplificado este importante instrumento de escritura de los Incas al punto de transformarlo en un juego de niños.

$\mathrm{Ni}$ se puede dejar de lado que el totalizador -aquel cordel que lleva los colores y la cantidad de toda la mercancía contada en un mismo quipu- por sumar objetos distintos pero pertenecientes a una misma etnocategoría, nos evidencia que la aritmética de los Incas era de conjuntos: tema que abre nuevas investigaciones sobre la matemática de los Incas de las cuales se tratará en otro artículo.

\section{2b. El miraypaquipu}

El miraypaquipu es en cambio algo nuevo, para nosotros: se trata de una "tabla" multiplicativa que se lee en Exsul Immeritus, (c.11r) y proporciona, como ejemplo, la "tabla" del n. 4. Es importante para nuestra investigación en cuanto evidencia, en el ámbito de los quipu de número, que el color puede substituir la posición para indicar las decenas (color rojo) y las unidades (color verde) (Fig. 4).

El hecho que el color pueda substituir la posición está en la línea que proporciona Cristóbal de Molina (1575) de un colgante de quipu con dos nudos que lleva insertadas hebras de colores y se observa, además, en varios quipu prehispánicos: como por ejemplo el cordel del quipu del museo Etnográfico de Berlín VA 415 y el del Museo de Dallas T41299.27.

\section{2c. El quipu ordinal}

Blas Valera (Exsul Immeritus, c. 9r) presenta y dibuja también otro tipo de quipu numérico, que denomina quipu ordinal: se parece al quipu utilizado hasta el siglo XX por pastores y que los estudiosos consideraban en cambio una

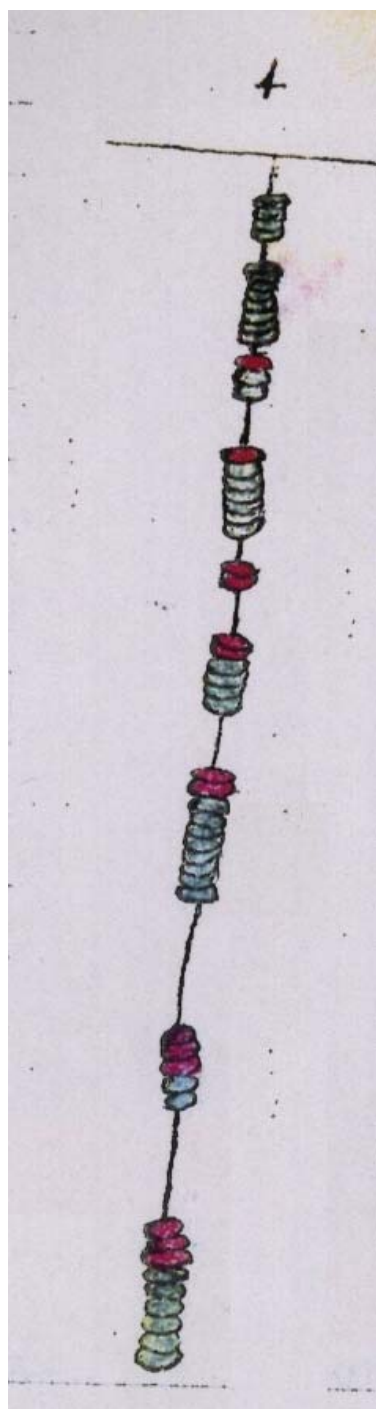

Fig. 4. Miraypaquipu. (Exsul Immeritus. Colección Miccinelli-Cera, Nápoles). forma deculturada de los quipu numéricos de posición ${ }^{11}$. El P. Blas lo llama ordinal porque refleja el orden (primero, segundo, etc.) con que se observan en el terreno, por ejemplo las filas de llamas. Según la misma fuente, estos quipu eran utilizados por la gente simple como los pastores. Sin embargo, el proyectar en el quipu las observaciones directas en el terreno, proporciona a quien lo observa la memoria topográfica y concreta

${ }^{11}$ Urton, 1995: 321.

75 Laura Laurencich Minelli. La escritura de los Incas a la luz de dos documentos... 68 a 89. 
de lo que se apunta (Fig. 5). De eso se desprende que el quipu ordinal no es una forma deculturada del quipu numérico pero otro tipo de quipu que utilizaba la gente simple. Sin embargo el quipu ordinal Inca lleva, a diferencia del quipu ordinal todavía en uso (siglo XX) un colgante totalizador (el n. 7 de Fig. 5) para el uso del inspector: colgante que pertenece, en cambio, al tipo de quipu numérico de posición ${ }^{12}$.
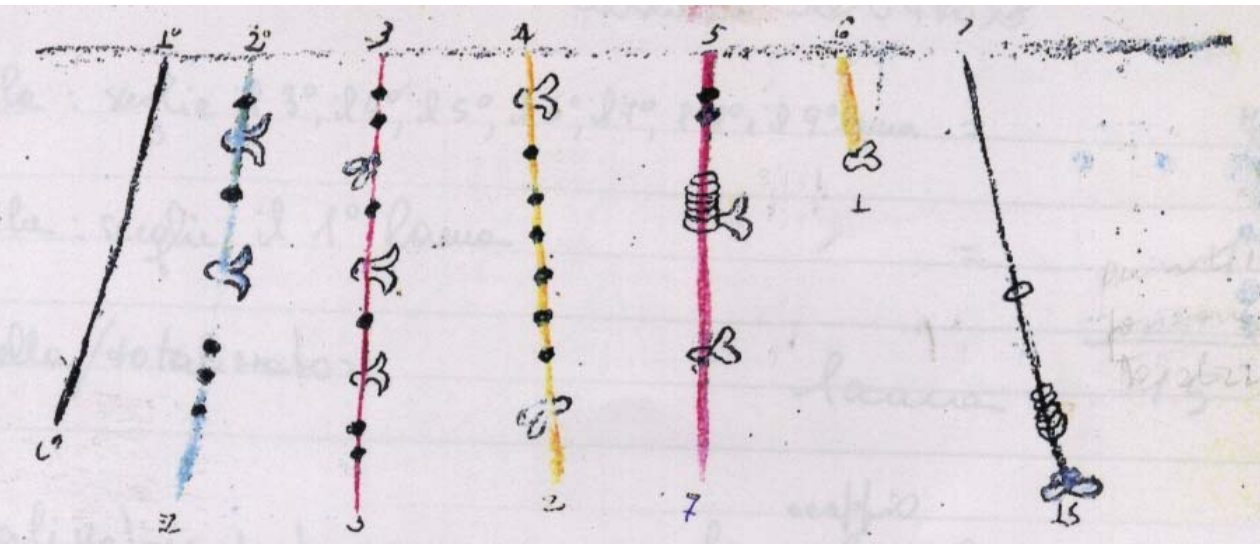

Fig. 5 Quipu ordinal (Exsul Immeritus- Col. Miccinelli-Cera, Nápoles).

\section{Los quipu de escritura}

Aquí refiero de aquellos quipu de escritura que Sempat Assadourian, al analizar a los cronistas Estete, Betanzos, Polo, Cieza, Garcilaso, etc., afirma haber sido bien conocidos por los Inca ${ }^{13}$ y que nosotros, gracias a Exsul Immeritus, ahora podemos llamar con sus nombres, es decir Capaquipu, Pachaquipu y Cequecuna cuando conciernen respectivamente con la nobleza, con el computo del tiempo y con los ceques.

\section{3a. El capacquipu o quipu real}

El ms. Exsul Immeritus (cc 9r-12v, Add. IV) llama capacquipu (quipu de la nobleza también dicho: quipu real) los quipu para registrar textos que refiere haber sido reservados a la nobleza. Quipu que, en su fase final, se reduce a número. Ni se puede dejar de lado que Montesinos confirma, en el libro I de sus Memorias Historiales, la queja de Blas Valera (EI c.8r) que Garcilaso no conocía dichos quipu puesto que tuvieron que mandarle unos "de que había mucho en el Perú y en la ciudad de Quito"14. Hecho que evidencia el uso todavía al final del siglo XVI de los capacquipu tanto en el Perú como en Quito al igual que la ignorancia de Garcilaso sobre el tema.

Para comprender a los capacquipu y a los números relacionados con este instrumento hay que acordarse de que, a la luz de Exsul Immeritus (Add. III), en el mundo andino los dioses y las fuerzas de la naturaleza no sólo son sacros sino que corresponden también a números (Fig. 6). Números que pertenecen a una curiosa aritmética que no está relacionada con los cálculos cotidianos sino con cálculos que Exsul Immeritus refiere como pertenecientes al Hananpacha (el mundo de arriba, el cielo con sus dioses): números que por lo tanto serían sacros ${ }^{15}$.

\footnotetext{
${ }^{12}$ Laurencich Minelli 2004b.

${ }^{13}$ Sempat Assadourian, 2002:122-139.

${ }^{14}$ Hyland 2002: 159.

${ }^{15}$ Exsul Immeritus, Add. II, Laurencich Minelli, 2012; Laurencich-Minelli y Rossi, 2007.
} 
El capacquipu о quipu real, cuya lectura refiere Exsul Immeritus haber sido siempre cantada, es uno de los varios quipu de escritura que en su fase final se reduce a un número. El capacquipu está caracterizado por símbolos textiles que Exsul llama ticcisimi (palabras claves) cuando son insertados uno a la vez en una cuerdecilla que cuelga desde la cuerda maestra a la manera de franja: en este caso su lectura es fonética (Fig. 6), Ticcisimi que tal vez corresponden también a los que Garcilaso ${ }^{16}$ llama señales $\mathrm{y}$, en su enredo de presentar la obra valerana en sus Comentarios, refiere: "que mostraban los hechos historiales hazañosos, o haber habido embajada, razonamiento o pláticas hecha en paz o en guerra" Además Exsul Immeritus nos informa que, cuando los mismos símbolos textiles son utilizados libres de la cuerda maestra, se llaman tocapu y su lectura puede ser conceptual, es decir, puede corresponder a una frase ${ }^{17}$.

Blas Valera (EI Add. IV) afirma que, según los amauta, los ticcisimi eran 200, de los cuales él

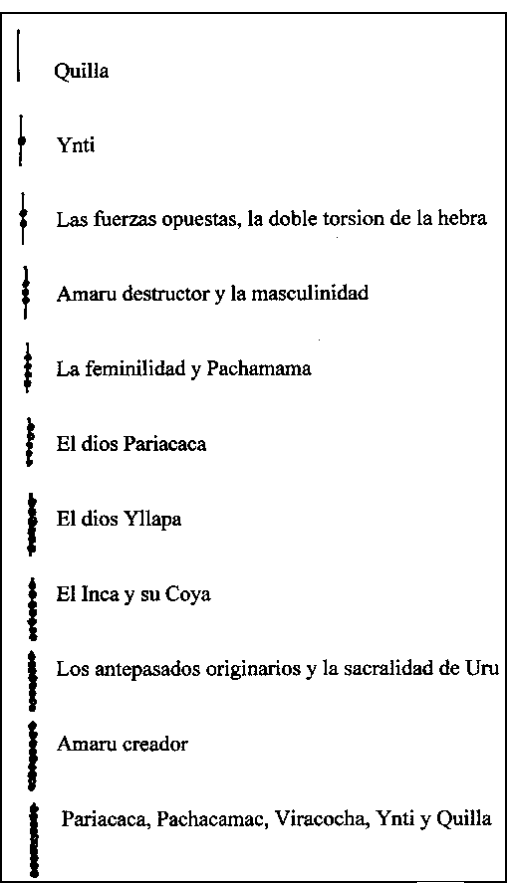

Fig. 6. Tabla de números sacros (L. Laurencich desde Exsul Immeritus). refiere haber conocido apenas 65 , y explica que podían ser de hilos anudados de varios colores, de tela, de metal y también de madera: estos últimos, bien pintados, cuenta que eran insertados en aquellos capacquipu que se utilizaban como ajuar de las momias reales, en cuanto se pensaba que solamente la madera podía contener y transmitir la sabiduría sobrehumana. Ticcisimi que luego (1637) Anello Oliva utiliza en la traducción del capacquipu Sumac Nusta pero en llave más cristiana (HR c.6v) (ver tabla comparativa de los ticcisimi (Fig. 7): eso nos dejar suponer que Oliva, después de la verdadera muerte de P. Blas (1619), intentó una forma más sincretística del antiguo culto proporcionado por el P. Mestizo.

El P. Blas anexa a Exsul Immeritus un quipu mixto (capacquipu + quipu numérico) en filigrana de oro $^{18}$ y unos ticcisimi sueltos que refiere el amauta Machaquymuqta habérselos entregados a su abuelo, el mago médico Illavanqa, como agradecimiento por haberlo curado de las heridas recibidas en la batalla de Chachapoyas entre la hueste de Atahualpa y la de Huáscar (EI c.2v, Add.VI): se trata de 12 ticcisimi, ya cada uno con su anillo de hilo como si fueran listos para ser insertado en un quipu. Ticcisimi que encajan tal vez con la descripción ambigua que de los "signos" proporciona Garcilaso ${ }^{19}$.

\footnotetext{
${ }^{16}$ Garcilaso de la Vega, Libro VI, cap. IX, 1609 (1977: 409).

17 Ejemplo de escritura mediante ticcisimi (Historia et Rudimenta, canto Sumac Nusta). Por ej.: si utilizamos el ticcisimi: Pachacamac que, subdividido en sílabas, es PA-CHA-CA-MAC, y con este queremos escribir mediante el capacquipu la palabra pacha (tiempo) hay que insertar, en la cuerda maestra, dos veces el ticcisimi Pachacamac: un nudo bajo el primer ticcisimi indica que la lectura es PA y dos nudos bajo el segundo indica la lectura CHA. Lectura que en total, por lo tanto, proporciona: PACHA (tiempo). En cambio, la lectura de la palabra maestra sin nudos proporciona la palabra en su forma entera: el dios PACHACAMAC.

${ }^{18}$ Laurencich Minelli, 2007a: 346-349.

${ }^{19}$ Garcilaso de la Vega, 1609 (1963: L.VI, cap. IX).
}

77 Laura Laurencich Minelli. La escritura de los Incas a la luz de dos documentos... 68 a 89. 


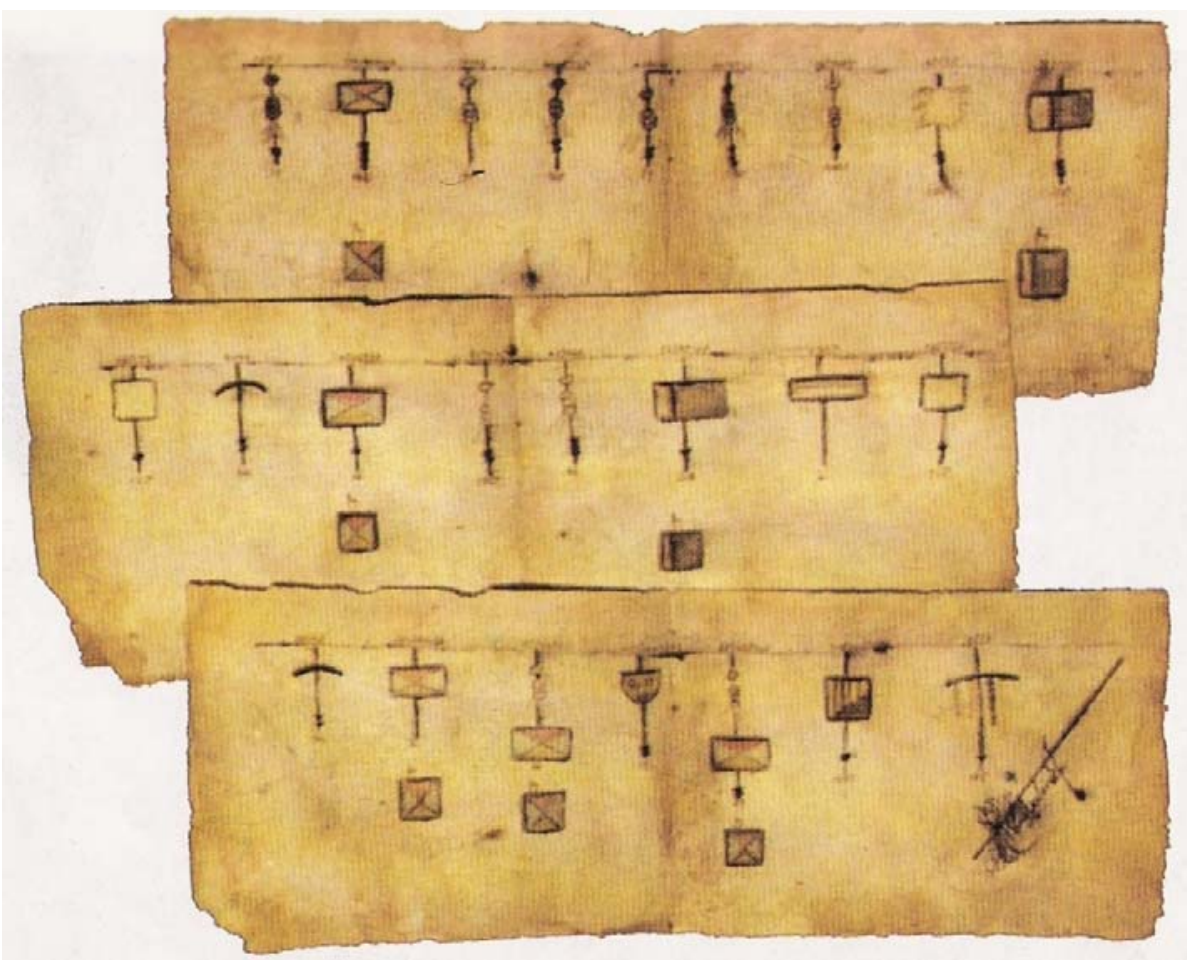

Fig. 7. Quipu Sumac Nusta (Historia et Rudimenta, col. Miccinelli-Cera, Nápoles).

La existencia de un capacquipu que es en parte quipu numérico indica que, también en los quipu de los Andes como en cualquier sistema escritorio, se pueden mezclar los textos con los números. El Padre Mestizo dibuja en Exsul Immeritus seis capacquipu que nos brindan la lectura fonética en quechua de seis textos: cinco de los cuales refiere que se cantaban en la escuela de la nobleza yachahuasi, para ser luego transformados en números que se calculaban mediante la yupana.

El canto más frecuente en el ámbito del grupo valerano es el canto quechua Sumac Nusta (Fig. 8), sin embargo lo encontramos, en forma de poesía escrita en letras latinas, en Garcilaso de La Vega ${ }^{20}$ mientras en forma de capacquipu, es repetido dos veces en el ms. Historia et Rudimenta (un fragmento textil y el canto entero dibujado sobre papel de mano y firma Blas Valera). Además lo hallamos una vez más, pero con los ticcisimi sueltos (esto es, dibujados sin la cuerda maestra) en el ms. Exsul Immeritus (Add. II). El mismo canto Sumac Ñusta, en la forma numérica proporcionada por su yupana, resulta pintado ya sea en Exsul Immeritus (c.9v), ya sea en la bien conocida figura del Contador y Tesorero de la Nueva Coronica (c.360), ya sea en el intento que proporciona Oliva (Historia et Rudimenta, 6vb) con el fin de aclarar los pasajes que se necesitan para transformar el canto en su número: el $n^{o} 5^{21}$. Todo eso nos deja suponer, en espera de ulteriores investigaciones, que el canto Sumac Nusta fuera el símbolo de la contestación Inca cristiana al Virreinato como se desprende desde el trabajo que tengo en preparación sobre eso y la Nusta Sumac.

Blas Valera (EI) nos informa además que la transformación de los ticcisimi del capaquipu en los tocapu, permitía la simbólica conexión entre el Hananpacha (el mundo de arriba) y la Pachamama, la tierra ordenada por el hombre; al mismo tiempo eso ofrecía al amauta el control de los tocapu en cuanto ya huaca, eso es números ya

\footnotetext{
${ }^{20}$ Ibid., 1609: XXVII.

${ }^{21}$ Laurencich Minelli, 2007a: 167-175.
} 
bien fijos en la Pachamama (la tierra antropizada del Tahuantinsuyu); en cambio el mismo amauta consideraba a los ticcissimi peligrosos cuando corren en el cielo (Hananpacha) sin control (Exsul Immeritus: Add. II).

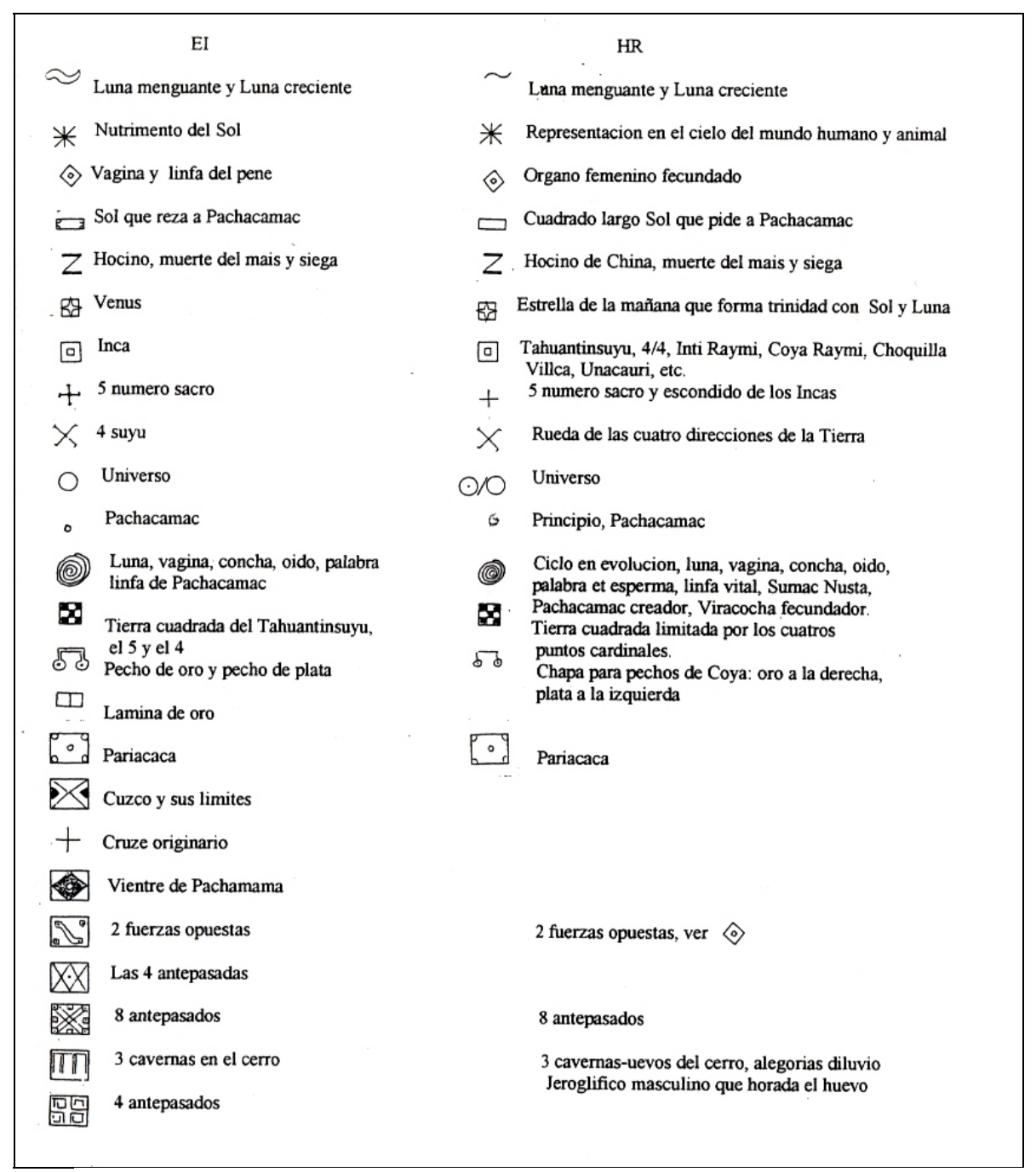

Fig. 8. Tabla comparativa de los ticcisimi cuales se desprenden desde EI y HR (L.Laurencich)

\section{3b. El pachaquipu o quipu calendarial}

El pachaquipu (Fig. 9) es otro quipu de escritura mixto que, de acuerdo a Exsul Immeritus (c.18”v), permitía al amauta, eso es al astrónomo Inca, la conexión entre el mundo de arriba, el Hananpacha, y la Pachamama, la tierra. Se trata de un quipu calendarial que es al mismo tiempo luni-solar, es decir respectivamente hurin y hanan como evidencian los colores de los ticcisimi insertados en sus cordeles y las "semanas" de 15 días que corren alternativamente con 15 nudos verdes (hurin) y 15 rojos (hanan). Este pachaquipu está pintado sobre papel por una persona que tuvo acceso a un pachaquipu Inca en cuanto se parece ya sea a dos quipu calendariales arqueológicos -el calendario del valle de Ica, de los tiempos Inca, y el de Chachapoya, de los tiempos de 
la entrada española- ya sea a la descripción del calendario luni-solar andino proporcionada por Polo de Ondegardo en $1559^{22}$.

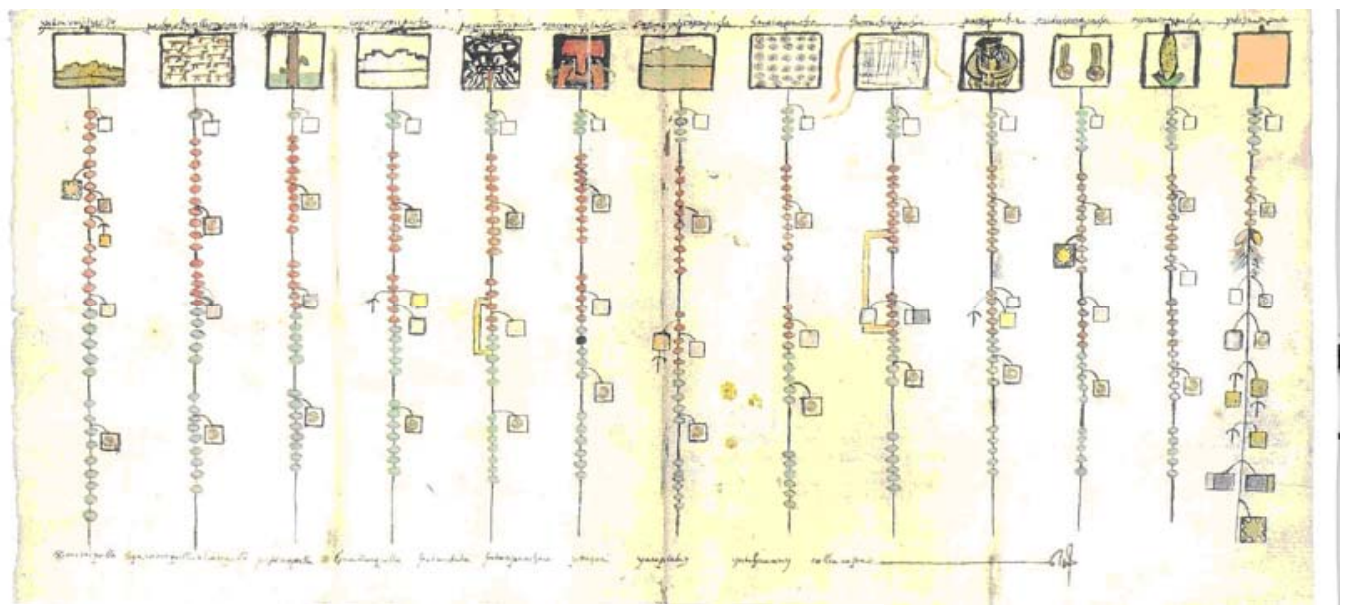

Fig. 9. Pachaquipu (Exsul Immeritus, col. Miccinelli-Cera, Nápoles).

El pachaquipu pintado en el ms. Exsul Immeritus concierne el año de la destrucción del Tahuantinsuyu (1532); además resulta ser un ejemplo muy interesante de cómo los Incas entendían el calendario del tiempo cósmico, pacha: esto es, un calendario que une el tiempo lunar = hurin, con el tiempo solar = hanan. Tiempos lunar y solar que, para los Incas, corrían independientes a pesar de estar unidos en el pacha, el tiempo cósmico. Los 13 ticcisimi encabezan cada uno de los 13 colgantes -que llamaremos "meses"-: ticcisimi que se pueden leer fonéticamente y al mismo tiempo en su forma conceptual. Unos ticcisimi insertados a lo largo de las colgantes apuntan los momentos astronómicos importantes como los solsticios, los eclipses y también las fases de la luna de cada "mes".

Muchos elementos curiosos aparecen al comparar este pachaquipu con los dos calendarios de la Nueva Coronica: el calendario de los rituales de cc. 235-259 y el calendario de cc. 1130-1166, que es un calendario al estilo del calendario agrícola europeo, pero para indicar los tiempos andinos de trabajo y al mismo tiempo compararlos con los meses y los santos cristianos. En otra oportunidad tratamos la comparación de los tres calendarios ${ }^{23}$ y aquí sintetizo que los resultados evidencian cómo los tres calendarios son complementarios entre sí: es decir, una vez más indican que los documentos Exsul Immeritus y Nueva Coronica han sido concebidos por una misma persona pero con destinatario distinto. En breve, resulta que por un lado tenemos el pachaquipu: el calendario luni-solar reservado a los amauta, cuyos ticcisimi insertados en las colgantes indican no sólo los días del pacha, es decir, del tiempo cósmico que corre en el Hananpacha, sino también cuando había que efectuar los cálculos astronómicos y astrológicos sobre los astros del tiempo cósmico para transformarlos en las más controlables huaca de la tierra y de esta manera equilibrar la conexión entre el Hananpacha y la Pachamama. Por otro lado, tenemos a los dos calendarios descritos y pintados en la Nueva Coronica (cc. cc.235-259; cc.1130-1166) que ofrecen, por separado, la escansión y la organización del tiempo en la tierra ordenada por el hombre. De eso se desprende que el tiempo de la Nueva Coronica, a pesar de no pertenecer al tiempo cósmico pacha sino al tiempo quilla, es decir lunar o

${ }^{22}$ Zuidema, 1989, 2003, 2004.

${ }^{23}$ Laurencich Minelli y Magli, 2007. 
de la tierra, es a su vez hurin en el calendario de los rituales y hanan en el calendario de las faenas agrícolas de la misma Nueva Coronica: lo que evidencia una vez más cómo hurin y hanan caracterizaban cualquier acto del mundo indígena ya sea en el Hananpacha ya sea en la Pachamama.

En resumen, el pachaquipu mira y maneja el pacha: el tiempo cósmico lunisolar del Hananpacha, como conviene a un calendario utilizado por los grandes amauta de la nobleza que habían salido de la escuela yachahuasi (EI c.5r). En cambio, los dos calendarios de la Nueva Coronica manejan el tiempo lunar, quilla, en la tierra, es decir la Pachamama, como haría no solo cualquier astrónomo -astrólogo que no pudo frecuentar dicha escuela, sino también de la forma que podía entender el Rey de España, destinatario de la Nueva Coronica: esto con el fin de que el Rey comprendiera por lo menos las analogías existentes entre el calendario inca lunar, dicho quilla, y los calendarios europeos ${ }^{24}$.

\section{3c. El Cequecuna o el quipu de los ceque}

El Cequecuna o quipu de los ceque es otro quipu mixto que Blas Valera nos proporciona pintado sobre papel (EI, c.12v) (Fig. 10). Representa de manera gráfica a los ceque de Cuzco: aquellas líneas que unían el Coricancha (el templo del Sol) con las 328 huaca. Sin embargo, ésta es la única figura de cequecuna que llegó hasta nuestros días y resulta estar estrictamente relacionada con la descripción del "mapa" que refieren los cronistas Polo de Ondegardo y Bernabé Cobo $^{25}$. El cequecuna de Exsul se presenta a la manera de un quipu numérico extendido en forma de estrella que proporciona apenas dos palabras claves o ticcisimi: "Inti " $=\mathrm{el}$ Sol y "Huaca". Inti es pintado en forma de un cuadrado que al mismo tiempo es el centro del cequecuna (como si fuera la cuerda maestra arrollada sobre sí misma) desde el cual nacen los cordeles del quipu que se extienden en forma de estrella y llevan el ticcisimi "Huaca" insertado al final de cada colgante: ticcisimi que tiene también la función de indicador de clase en cuanto

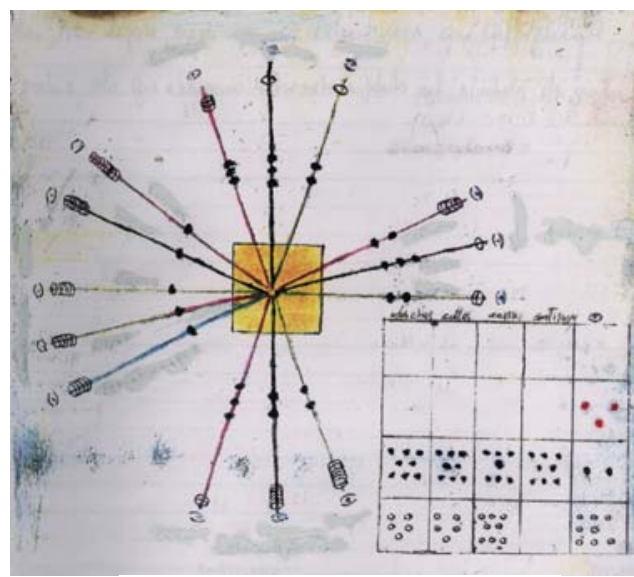

Fig. 10. Cequecuna (Exsul Immeritus, col. Miccinelli-Cera, Nápoles).

evidencia que los números allí anudados corresponden al número de las huaca que se pueden contar en cada colgante del quipu. Una yupana de 5 columnas dibujada a un lado del cequecuna proporciona una vez más el cuadro del número de las huaca repartidas según los 4 suyu del Imperio Inca, mientras que la última columna, la $5^{\circ}$, cuenta el total de las huaca: 328. En otras palabras, el quipu de los ceque sintetiza el culto de las 328 huaca del Cuzco proyectándolas en la entera cosmología del Tahuantinsuyu y también en la organización social de Cuzco, como se desprende desde la Fig. 10 en la cual los cordeles de color verde corresponden al Chinchasuyu, los de color negro al Contisuyu, los rojo al Antisuyu y los celeste al Collasuyu. La lectura de este geo-quipu, de acuerdo a Exsul Immeritus, es que el cequecuna conecta el Sol, es decir el centro del Hananpacha, con las 328 huacas del Tahuantinsuyu ordenadas como

\footnotetext{
${ }^{24}$ Laurencich Minelli y Magli 2007.

${ }^{25}$ Zuidema 1995, 1989.
} 
sigue: 165 huaca pertenecen a la mitad hurin y 163 a la mitad hanan. De éstas, 85 huaca son del Chinchasuyu, 85 del Contisuyu, 78 del Antisuyu, 80 del Collasuyu. Para más detalles ver un trabajo anteriori ${ }^{26}$ y subrayo que el cequecuna de Exsul Immeritus ya no insiste en los grupos aristocráticos que tenían el cargo de las huaca cuanto en el número 328, el número total de las huaca: esto tal vez porque, a causa de la conquista hispana, la antigua aristocracia perdió peso. La síntesis de la lectura del cequecuna es por lo tanto que las 328 huaca equilibran el dualismo entre el Hananpacha, expresado por el Sol, Inti, y el Cuzco, el centro de la Pachamama, la tierra antropizada.

Una vez más, veamos números que se transforman en huaca para equilibrar la conexión entre el Hananpacha y la Pachamama, utilizando en este caso ya sea un quipu de escritura, ya sea un quipu numérico de posición pero también la yupana: yupana que al mismo tiempo indica los números de las huaca que ordenan la Pachamama y ordena la Pachamama misma al cuadricularla gracias a sus huaca.

\section{El estado de la cuestión}

Al concluir este artículo se plantean varias perspectivas de las cuales evidencio apenas las que aparentan una conexión significativa con el mundo jesuítico y dejo a un lado otros puntos como por ejemplo el examen del tiempo cósmico pacha y del tiempo quilla, es decir lunar o de la tierra: el primero hanan y el segundo hurin. Tiempos que serán objeto de otra publicación más detenida.

Lo que sobresale, en el ámbito jesuítico, es el hecho que, para comunicar con el mundo nativo, organizaron no solo el bien conocido Quechua General pero un grupo de ellos propuso lo que yo llamaría Escritura General de la cual en este artículo se presentan unos rasgos. Escritura que, relacionada con el mundo indígena, es una síntesis desde los quipu pre-hispánicos todavía en uso durante la segunda mitad del siglo XVI: escritura de la cual resulta que el P. mestizo Blas Valera ha sido, con el H. Gonzalo Ruiz, el organizador y Anello Oliva el difusor. Se trata de un sistema de escritura de carácter prevalente textil, reservado a la nobleza, que en paralelo con el Quechua General, unifica varias grafías entre las cuales los ideogramas y varios tipos de quipu para registrar no solo números sino también textos. Escritura que a la luz de las fuentes jesuíticas Exsul Immeritus de mano de Blas Valera e Historia et Rudimenta de mano predominante del bien conocido P. Anello Oliva, interesaba de manera específica al grupo de jesuitas relacionados con el gobierno del enclave inca, dicho "Reino" de Paititi y que, en los primeros tiempos de la Colonia cuando el P. mestizo Blas Valera intenta explicarlas, se integraban todavía una con otra y se unificaban en la forma numérica; es decir, se presentaban como un posible sistema único de escritura con base numérica. Números que en este sistema de escritura descrito por el P. Valera eran concebidos como seres vivientes que animaban o destruyan al mundo, de acuerdo al amauta que los gobernaba. Eso nos permite arriesgar la hipótesis de trabajo que el Tahuantinsuyu ya había tenido, en tiempos pre-hispánicos. Sistemas de escritura de base numérica con varios aspectos gráficos de expresión, como sugieren los puntos 2 y 3 de este articulo: escritura que interesó de manera específica al grupo de jesuitas en lo que concierne al "Reino" inca cristiano de Paititi, en cuanto sus raíces estaban en el antiguo Tahuantinsuyu, y que los jesuitas uniformaron de manera paralela a cuanto hicieron con el Quechua General. Sin embargo la situación política de la primera parte del siglo XVII en el Virreinato del Perú que ya no permitía al grupo jesuita de gravitar

${ }^{26}$ Laurencich Minelli, 2004b, 2007a: 143-145.

82 Laura Laurencich Minelli. La escritura de los Incas a la luz de dos documentos... 68 a 89. 
ni en el Cuzco, por haber sido conquistado e hispanizado, ni en Vilcabamba, por haber sido destruida por los hispanos en 1572, en cambio Paititi (Bolivia), bien alejado del mundo hispano, era todavia la proyección más hacia el Este, es decir hacia el Sol naciente, de lo que quedaba del ya "reino" Inca cristiano de Vilcabamba. Por lo tanto un grupo jesuita intentó establecer un "Reino" Inca cristiano del cual refiere, en forma secreta, el documento Exsul Immeritus al igual que Historia et Rudimenta y la Nueva Coronica. Reino Inca cristiano que proporciona un cristianismo curioso: es decir una continuación del culto Inca y por eso supuestamente bien acepto por la nobleza Inca colonial $^{27}$. A eso hay que añadir que el simbolismo de la búsqueda del Sol Niño, es decir la migración de la nobleza Inca hacia el Paititi, eso es hacia el Este, que concierne con este Reino, era una forma patente de buscar al nuevo Sol, el Sol del Este, el Sol Niño: es decir buscar la raíz de las tradiciones andinas y renovarlas mediante el cristianismo.

Lastimosamente no hemos hallado todavía ninguna documentación ulterior sobre el tema del Reino Inca cristiano de Paititi a parte el hecho que en 1737 resulta ya cancelado como herético: como se desprende desde las palabras crípticas que escribe el P. Pedro de Illanes en su breve cierre del ms. Historia et Rudimenta en $1737^{28}$. ¿Cuál ha sido la herejía que condenó al "Reino de Paititi"? A este punto hay que detenerse un momento sobre el hecho que el P. Illanes recibe el ms. Historia et Rudimenta de las manos ya "heréticas" del indio Juan Taquic Menendez de Sodar para "venderlo" ocho años después en Nápoles al Principe di Sansevero (el 25 de octubre de 1745) que lo utiliza en su Lettera Apologetica (1750: 242-243) como los estudiosos del napolitano Raimondo di Sangro Principe di Sansevero bien conocen.

Al volver al Paititi, quizás los capacquipu pueden haber sido una de las herejías que lo condenaron en cuanto los capacquipu y otros quipu de escritura no habían sido aceptados por el Concilio Límense. Por cierto las causas reales que se esconden tras esta condena son mucho más complejas y piden una atenta investigación puesto que los сарасquipu, pachaquipu у сеquecuna, es decir respectivamente los quipu reservados a la nobleza, los quipu calendarios y los quipu para escandir los ceque están presentados de manera nebulosa en la cronaquistica que conocíamos: eso antes de encontrarlos descritos de manera suficientemente clara en el ms. Exsul Immeritus.

Sin embargo el manuscrito Exsul Immeritus de mano del P. Valera, nos abre una pequeña ventana sobre la gran variedad y el potencial de los quipu que se utilizaban en el mundo Inca y que se utilizaron luego en el "Reino" de Paititi: eso a pesar de que ni Blas Valera ni Anello Oliva aclaran hasta cuál punto el Reino de Paititi funcionó pero las dos figuras de Paititi que Blas Valera dibuja en Exsul Immeritus, evidencian que el Reino de Paititi se realizo’ (Fig. 11 y 12). Además unos posibles

\footnotetext{
${ }^{27}$ Laurencich-Minelli 2011.

${ }^{28}$ El P. Illanes, al revelarnos que el manuscrito ha sido entregado en la Concepcion, y de manera especifica en la Sacristía de la Iglesia de S. Francisco Javier de la Compagnia y no en la Iglesia misma, aclara, a quien sabe de cosas eclesiasticas, que el manuscrito, su contenido y el indio quien lo llevaba eran hereticos hasta despues de la confesion y de la entrega al confesor del manuscrito mismo. HR: "El indio Juan Taquic Menendez de Sodar me hizo entrega en el momento de su muerte de este manuscrito, en la Sacristía Ecclesia S.Fran.i Saverij S. Jesu de Conceptione de Chille. Juan Taquic despues de haberse piadosamente confesado, me confió una bolsa que contenia una pequeña imagen del S.S. Rosario, algunos fragmentos de quipu y este manuscrito. Cuanto mas lo leo, la lengua latina y el estilo que empleó me hacen cie(r)tamente suponer que el autor era un Clérigo; las inicial(es) Jac. hacen pensar que el nombre sea Jacinto o Jacob. Quienquiera que sea, ha escrito una pagina de historia verdaderamente dramatica: es poco, sin duda, lo que queda de la antigua "Jerusalem" sobre la cual pasaron poderosos y devastadores Conquistadores. Dios los tenga en su misericordia! A.D. MDCCXXXVII. Petrus de Illanes, IHS ."
}

83 Laura Laurencich Minelli. La escritura de los Incas a la luz de dos documentos... 68 a 89. 
indicios hallados en la Bula Pontificia, en idioma Quechua, del Papa Clemente VIII (1603) está también en favor de la realización del "Reino" de Paititi" ${ }^{29}$. En el mismo rumbo esta un documento de 1584 de mano del P. Andrés López, el maestro de Blas Valera, recién hallado en el archivo romano de la Compagnia $^{30}$, que plantea en contraluz que el Paititi de P. Blas ha sido la continuación del Paititi de su maestro, el P. Andrés López. Eso sugiere que P. Blas aprovechó de la autorización que P. López había recibido en 1584 de las manos del Papa (Gregorio XIII) para enviar misioneros al Paititi; autorización que justifica una vez más el interés de P. Blas para el Paititi al igual que su intento de mantener los antiguos proceso mentales y lógicos quechua: eso es la lógica holística del mundo andino ${ }^{31}$.

Lógica holística que nos deja suponer que lo que escribe Blas Valera en Exsul
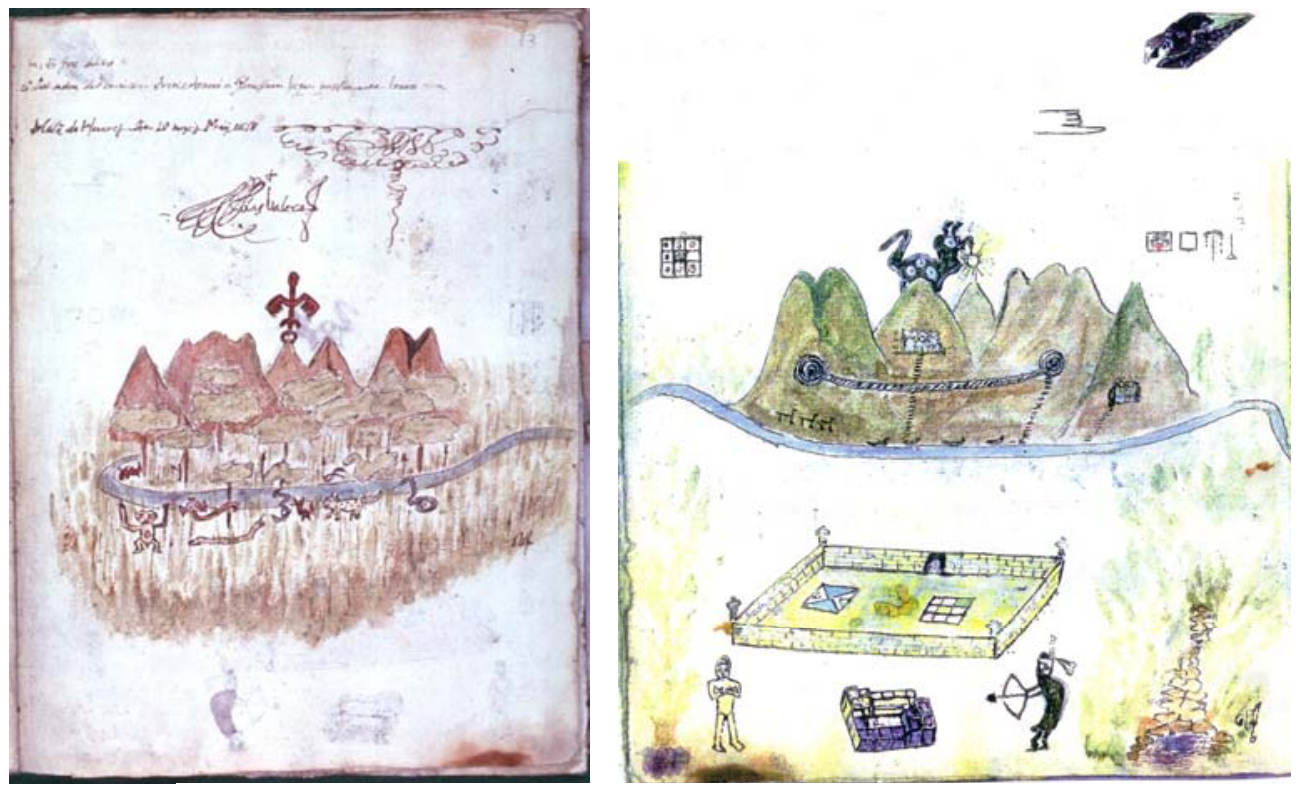

Fig. 11 y 12. Paititi desde las llanuras y desde los cerros (Exsul Immeritus, col. Miccinelli-Cera, Nápoles).

${ }^{29}$ Gnerre: 2007.

${ }^{30}$ Polia, 2011.

${ }^{31}$ La lógica holística o transformativa (Desweux 2001, Laurencich-Minelli 2005) caracteriza al mundo Inca al igual que lo de América indígena. Es una lógica aparentemente incomprensible si la examinamos con nuestra lógica lineal, inductiva y deductiva. La lógica holística actúa en cambio según un proceso amebiforme, ampliándose en una especie de juego de espejos, en el cual el número de los dioses y de las fuerzas divinas se suman formando un todo divino amplio y abarcador. Lógica que se comprueba en los curiosos cálculos de los números sagrados incas evidenciados en Exsul Immeritus, en las maneras de sumarse entre ellos, maneras que tienen los dioses y las fuerzas divinas bajo forma de números sagrados no sólo en el ámbito del sacro andino sino también del mundo mesoamericano, como se desprende del calendario ritual mesoamericano del tonalpohualli dando lugar a lo que con nuestra lógica lineal, solemos llamar aspectos de una divinidad, pero que en realidad son divinidades distintas en continuo cambio, según el proceder de los días y al mismo tiempo partes del todo. Lógica que foma el sustrato de todo el mundo indígena y que he constatado aún viva en las figuras lingüísticas de los actuales Guaymí del área Intermedia, entre los cuales sonido, figura y concepto están cambiando y sumándose entre sí sin parar, sin poderse fijar y abstraer al escribirlos mediante nuestras letras del alfabeto. Lógica que nos presenta a la sociedad andina tradicional como un ser vivo textil que es persona y al mismo tiempo es parte del todo (Arnold et al. 2000). Lógica que Desveux (2001), concede a la mitología, a los rituales, a la sociología, incluso a los términos de parentesco en una relación transformativa entre sí y que está relacionada con el proceso mental de las lenguas americanas que son aglutinantes, es decir, que añadiendo infijos o sufijos a una palabra, ésta cambia su significado. Lógica que privilegia la sociedad como una totalidad y no como un conjunto de personas y lleva a vivir el mundo sagrado poblado por una miríada de divinidades y de fuerzas sagradas que actúan como una compleja totalidad

84 Laura Laurencich Minelli. La escritura de los Incas a la luz de dos documentos... 68 a 89. 
Immeritus es, como él afirma, realmente su síntesis desde los quipu pre-hispánicos todavía en uso durante la segunda mitad del siglo XVI. Síntesis que por lo tanto seria un reflejo lo que eran los quipu en el mundo Inca prehispánico y nos deja aun entrever la enorme flexibilidad y variedad de este sistema de escritura al apoyar, una vez más, nuestra hipótesis de trabajo que la fuerza del imperio teocrático del Tahuantinsuyu y del "Reino" colonial de Paititi era el producir números: números y con ellos la amplia comprensión de la numerología y de la contabilidad, que eran supuestos ser cosa animada que unificaba la vida cotidiana al igual que la cosmología de los Incas coloniales.

Ni se puede dejar a un lado el hecho que el Reino de Paititi narrado por el P. Valera, ha sido una de las causas de su exilio y al mismo tiempo de su regreso al Perú. Sin embargo era peligrosísimo, en el ámbito del Virreinato del Perú, la propuesta de un enclave indígena (el Reino de Paititi) en oposición al mismo Virreinato del Perú tanto que como consecuencia el P. Blas ha sido exiliado. Al mismo tiempo este "Reino" ha sido la razón luego del regreso al Perú de P. Blas como muerto redivivo y bajo el nombre nativo de la lora de su abuelo: Ruruiruna. "Reino" Inca cristiano que los jesuitas romanos, entre los cuales el P. Mutio Vitelleschi, querían establecer en el ámbito del Virreinato del Perú y en oposición al poder hispano hasta por lo menos el año 1617, cuando el P. general Mutio Vitelleschi efectuó sin testigos, la quema de los documentos del archivo jesuítico romano para el "bien de la Compagnia"32 Quema que, en mi opinión, por un lado marca el final del "Reino" inca cristiano de Paititi y por el otro justifica el hecho que el ms. Exsul Immeritus, escrito en 1618, eso es un año después de la quema romana, no se halle en el archivo jesuítico romano: es decir probablemente no lo alcanzó en cuanto el P. Vitelleschi no lo mandó a recoger: como en cambio pedía el P. Blas ya sea en Exsul Immeritus (EI: 4r), ya sea en la carta del 25 de junio de 1618, que le envía con este propósito al P. Vitelleschi durante los tres meses de redacción de Exsu1 Immeritus (Alcalá de Henares, 10 de mayo -2 de julio 1618); carta custodiada en el archivo romano del $\mathrm{ARSI}^{33}$.

El tema de la escritura quechua mediante quipu que el P. Blas presenta en Exsul Immeritus, es también muy importante en cuanto nos proporciona la fuente actualmente más diversificada sobre eso y al mismo tiempo sugiere una posible aculturación cristiana a causa de la época colonial en el ámbito del "Reino" nativo de Paititi. Si dicha aculturación se realizó, ha sido todavía muy superficial en cuanto el texto valerano refleja todavía el pensamiento holístico de los Incas puesto que el P. Blas simplemente organizó el quechua colonial de los Inca con el fin de tener no solo un instrumento que le permitiera la recíproca comunicación con los Andinos sino también proporcionar el idioma quechua como idioma del "Reino" de Paititi con su antigua forma de escritura mediante quipu, ideogramas y pictografías. En otras palabras este tema de la escritura quechua, que unificaba la vida cotidiana y la cosmología -el Hananpacha y la Pachamama- y al mismo tiempo mantenía unido lo que quedaba en el siglo XVII del Tahuantinsuyu mediante la curiosa lógica transformativa de los nativos, sugiere que el "Reino" Inca colonial de Paititi quería mantener la cultura Inca al igual que sus antiguos procesos mentales y lógicos.

\footnotetext{
${ }^{32}$ Laurencich 2007b:180-183, 2014, Bongiorno: 2007:260-263.El P. Mutio Vitelleschi, el sexto P. general de la Compagnia (Roma 1563-1645) entra en la Compagnia en el 1583: ha sido el maestro del P. Anello Oliva, en 1615 es nombrado P. General y su meta, desde aquel entonces, es el desarrollo planetario de la Comagnia.

${ }^{33}$ Gnerre: 2001.
}

85 Laura Laurencich Minelli. La escritura de los Incas a la luz de dos documentos... 68 a 89. 
La breve descripción del intento de P. Blas de organizar la escritura Inca evidencia una vez más que el jesuita mestizo profundizaba mano a mano el problema y que le dedicó su vida entera a partir de su juventud (Exsul Immeritus, cc.4r-4v, Add. IV). Sin embargo, su trabajo resulta más filológico y menos sincrético a la luz de sus discusiones sobre el origen y el uso de varias palabras quechua, con respecto a los intentos de otros autores contemporáneos, como por ejemplo Juan Santa Cruz Pachacuti, en cuanto encaja no sólo con lo que escriben los cronistas sino también con la documentación museística sobre los quipu arqueológicos y con la lógica holística del mundo andino.

Todo esto plantea una vez más la urgencia de investigaciones en los museos con la mente abierta a la gran variedad de quipu que pueden haber sido producidos por los Incas. Si alguien, sin conocer la descripción que de los quipu proporciona Exsul Immeritus, hubiera encontrado el susodicho fragmento del capacquipu Sumac Ñusta de la Fig. 8 en una investigación museística: ¿cómo lo habría clasificado, en el rumbo de los estudios empezados por Locke que plantean únicamente quipu numéricos y de posición? Probablemente como un adorno, por tener casi nada en común con el conocido quipu numérico: eso es en la misma línea del conquistador Alonso Valera, padre de Blas, que como escribe el mismo Blas Valera (EI, Add. IV), regaló a su madre un capacquipu a manera de faja para adornar su ropa: lo que hizo reír a su abuelo Illavanqa ante la ignorancia del hombre hispánico.

De todos modos la lucha del grupo jesuítico valerano para realizar una Reducción Inca cristiana en la Provincia Peruviana abre una página gloriosa y poco conocida de una parte de la Compagnia hacia la cultura Inca colonial y al mismo tiempo nos deja vislumbrar lo que era la antigua escritura de los Inca mediante quipu y abre la vía hacia ulteriores investigaciones sobre este complejo sistema de escritura.

\section{Bibliografía}

\section{Obras manuscritas}

Cumis, Antonio y Oliva, Anello, (final siglo XVI-1638): Historia et Rudimenta Linguae Piruanurum IHS, con añadidos de los siglos XVIII e XX (Napoli, Archivio Miccinelli).

Boan Juan Fernandez (de) Lic., (1610), Carta al Conde de Lemos, Ciudad de Los Reyes, 28 de marzo 1610, scritture Diverse n.2; (1611) carta al Conde de Lemos, Ciudad de Los Reyes, 31 de octubre 1611, Scritture Diverse, n.5 (Napoli, Archivio di Stato, Segreteria del Vicerè)

Oliva Anello (1631), Historia del Reino y Provincias del Perú. Vida de Varones ilustres de la Compañía de Jesús en el Perú repartida en cuatro libros, 1631, Add. Mss. 25327 (Londres, National Library)

Sangro, Raimondo Principe di San Severo (1745): Contratto notarile stipulato fra don Raimondo di S Sangro e P. Illanes, 25. 10. 1745, allegato alla scheda 35, notaio Francesco De Maggio, 1771m, Napoli, Archivio Notarile Distrettuale.

Valera, Blas (1618), Admodum Reverende Pater in Chirsto, Alcalae, VII Kalendas Iulias 1618, Archivum Romanum Societas Iesu, ARSI, Vol. Cast. 33, f.139, Roma 
Valera, Blas (1618), Exsul Immeritus Blas Valera populo suo, Napoli, Archivio Miccinelli-Cera. Alcalae,a.d. VI, Nonas Julias 1618.

\section{Obras impresas}

Acosta, José de, (1962) [1590], Historia Natural y Moral de las Indias, México D.F.; Fondo de Cultura Económica.

Anónimo (1586), Arte de la lengua general del Perú llamada Quichua, Los Reyes: Imprenta de Antonio Ricardo

Ascher, Marcia y Ascher, Robert (1969), "Code of Ancient Peruvian Knotted Cords (Quipus)”, Nature 222, pp. 529-533.

(1975), “The quipu as a visible language", 9, Visible language No. 4, pp. 229-356.

(1978), Code of the Quipu: Databook, Ann Arbor: University of Michigan Press.

(1986), "Mathematical Ideas of the Incas", Native American Mathematics, Austin: University of Texas Press, pp. 261-289.

Assadourian, Carlos Sempat (2002), "String Registries: Native Accounting and Memory according to the Colonial Sources", Narrative Threads. Accounting and Recounting in Andean Khipu, Quilter and Urton eds,, University of Texas Press, Austin, pp. 119-150.

Bauer, Braian S. (1992), "Ritual Pathways of the Inca: an analysis of the Collasuyu Ceques in Cuzco", Latin American Antiquity 3 (3): 183-205.

(2016), "The Cuzco ceque system as shown in the Exsul immeritus Blas Valera populo suo", Nawpa Pacha, 36:1.

Cantù, Francesca (2001), "Guaman Poma y Blas Valera en contraluz: los documentos inéditos de un oidor de la Audiencia de Lima", Actas del coloquio Internacional: Guaman Poma y Blas Valera. Tradición Andina e Historia Colonial: 475-519. F. Cantù, ed., Instituto Italo-latinoamericano IILA, Roma, 29-30 Settembre 1999, Pellicani, Roma.

Conklin William J. (1982), "The Information System of Middle Horizon Quipus", Ethnoastronomy and Archeoastronomy in the American Tropics, ed. A.F. Aveni \& G. Urton. New York, Annals of the New York Academic of Sciences, Vol. 385.

Desveux, Emmanuel (2001), Quadratura americana. Essai d'antropologie lévistraussiane, Genève: Georg. Collection Ethnos.

Garcilaso de La Vega (1963) [1609], Comentarios reales de los Incas, parte I. Obras completas del Inca Garcilaso de la Vega II, Biblioteca de Autores Españoles 133: 1-40. Atlas, Madrid.

Gnerre, Mauricio (2001), "La telaraña de las verdades: El f. 139 del tomo Cast. 33 del Archivum Romanum Societatis Iesu (ARSI)". Actas del coloquio Internacional: Guaman Poma y Blas Valera. Tradición Andina e Historia Colonial: 195-246. IILA, Roma, 29-30 Settembre 1999, ed. F. Cantù, Pellicani, Roma. 
(2007), Una bula pontificia de 1603 en quechua, Sublevando el Virreinato. Documentos contetatarios a la historiografia tradicional del Peru' Colonial. Laurencich y Numhauser eds., pp. 339-351.

Guaman Poma de Ayala, (1980) [1615], Nueva Corónica y Buen Gobierno, Siglo XXI, México, (3 voll.).

Hyland Sabine ( 2002), The Jesuit and the Incas. The extraordinary life of F. Blas Valera S.J. The University of Michigan Press: Ann Arbor.

Laurencich-Minelli Laura (1999), "La "culpa" del cronista peruano Blas Valera", Anales Museo del America, nº, pp. 95-110.

(2001b), "Un aporte de "Exsul Immeritus Blas Valera populo suo" y de "Historia et Rudimenta Linguae piruanorum" a la historia peruana: la figura de Blas Valera." Actas del coloquio Internacional: Guaman Poma y Blas Valera. Tradición Andina e Historia Colonial. IILA, Roma, 29-30 Settembre 1999, F. Cantù, ed, Pellicani, Roma, pp. : 247-272.

(2003b), Nuevas perspectivas sobre los fundamentos ideológicos del Tahuantinsuyu: lo sagrado en el mundo Inca de acuerdo a dos documentos jesuíticos secretos. Espéculo 25, Universidad Complutense, Madrid, http://www.ucm.es/info/especulo/numero25/tahuan.html

(2004b), "El curioso concepto de "cero concreto" mesoamericano y andino y la lógica de los dioses Números incas: una nota", Especulo 27, Revista de la Universidad Complutense, Madrid, http://www.ucm.es/info/especulo/numero27/cero.html.

(2004c), "Quipu y escritura en las fuentes jesuíticas en el virreinato del Perù entre el final del siglo XVI y la primera mitad del siglo XVII", El Silencio protagonista. El primer siglo jesuita en el Virreinato del Perù. 1567-1667, Eds. L. Laurencich-Minelli y P.Numhauser, ABYA AYALA, Quito, pp. 171-212.

(2005), "El mito utópico de Paititi desde un documento jesuítico parcialmente inédito del siglo XVII", Firenze, Archivio per l' Antropologia e la Etnologia. CXXXV: pp.183-204.

(2006b), "Hebras, quipus y tocapus en el mundo inca y colonial", Actas de la III Jornada Internacional sobre textiles precolombinos. V. Solanilla, ed. Barcelona, Dep D’ Art de la Universitat Autonoma de Barcelona-Institut Cabalá de Cooperacion Iberomericana.

(2007) (ed.) Exsul Immeritus Blas Valera Populo Suo e Historia et Rudimenta Linguae Piruanorum. Indios, gesuiti e spagnoli in due documenti segreti sul Perù del XVII secolo. Bologna, CLUEB.

(2009) Exsul Immeritus Blas Valera Populo Suo e Historia et Rudimenta Linguae Piruanorum. Nativos, jesuitas y espanoles en dos documentos secretos del siglo XVI. Chachapoya Municipalidad Provincial.

(2010), "Una nota sobre la araña mitica en el mundo andino prehispanico", Tupac Yawri. Revista Andina de Estudios Tradicionales. Mitos, Simbolos, Ritos, n.2, 2010 2009. Cuzco.

(2012), "Paytiti a través de dos documentos jesuíticos secretos del siglo XVII", en: Paititi. Ensayos y documentos, Isabelle Combès y Vera Tyuleneva 
(Eds.), Instituto de Misionología, Editorial Itinerarios, Calle Oruro E-0492 esq. Av. Ramón Rivero, Casilla 334; telf./fax: 00591-4-4522670, pp. 116-157.

(2014), "El manuscrito De las costumbres antiguas de los naturales del Pirú: un enfoque nuevo sobre su historia y autoría." ANUAC, Vol, III, Num, 2, dec., ISSN 2239-625X > pp. 1-34. www.rivistanuac.eu

Laurencich-Minelli Laura y Magli, (2007), “A calendar quipu of the early seventeenth centrury and its Relationship with Inca astronomy", in: Archeoastronomy, Journal of Astronomy, Vol. XXII, 2009 (2011) pp. 112-130.

Laurencich-Minelli L., y Rossi, E. (2007), "La yupana de la Nueva Coronica y las yupanas de Exsul Immeritus Blas Valera populos suo, abaco y escritura jesuitica o sincretismo jesuita?", Sublevando el Virreinato: documentos contestatarios a la historiografia tradicional del Peru' Colonial, Laurencich Minelli y Numhauser ed.,pp. 375-423, Abya Yala, Quito.

Locke, Leland (1912), "The Ancient quipu. A Peruvian Knot Record", American Anthropologist 14, pp. 325-332.

(1923), “The Ancient quipu or Peruvian knot record, New York”, American Museum of Natural History.

Molina Cristóbal de, (1916) [1575], Relación de las fábulas y ritos de los Incas (...), Los Pequeños grandes libros de Historia Americana, serie I, n. 4, Lima: Imprenta Sanmartí y Ca.

Radicati di Primeglio, Carlos (1979), El sistema contable de los Incas, Lima: Librería Studium.

Salomon, Frank (2002), "Patrimonial Khipus in a Modern Peruvian Village: An Introduction to the Quipocamayos of Tupicocha, Huarochiri'”. En: Narrative Threads: Accounting and Recounting in Andean Khipu: 293-319. Eds. J. Quilter e G. Urton, Austin, University of Texas Press.

Urton, Gary (1995), "A new Twist in old Yarn: Variation in Knot Directionality in the Inka Khipus”, Baessler-Archiv, Band XLII, Heft 2, Berlin, pp. 271-305.

$$
\text { (2003), Signs of the Inka Khipu, University of Texas Press, Austin. }
$$

Zuidema, Reiner Tom (1977), “The Inca Calendar" Native American Astronomy: 219259. Ed. A. Aveni, Austin, University of Texas Press,.

(1989), "A Quipu Calendar from Ica, Peru, with Comparison to the Ceque Calendar from Cuzco", World Archeoastronomy, A. F., Aveni ed., Cambridge University Press, Cambridge, pp. 341-351.

(2003), "Los días de la Epacta e Epagónimos en calendarios pre-hispánicos y según opinión de cronistas", Atti del Colloquio Internazionale Il Sacro e il Paesaggio: 333-342. Curatori D. Domenici, C. Orsini, S. Venturoli, CLUEB, Bologna.

(2004), "El quipu dibujado calendárico llamado pachaquipu en el documento Exsul Immeritus de la colección Miccinelli. El Silencio protagonista. El primer siglo jesuita en el Virreinato del Perù: 1567-1667': 172-212. Quito, ABYA AYALA, 